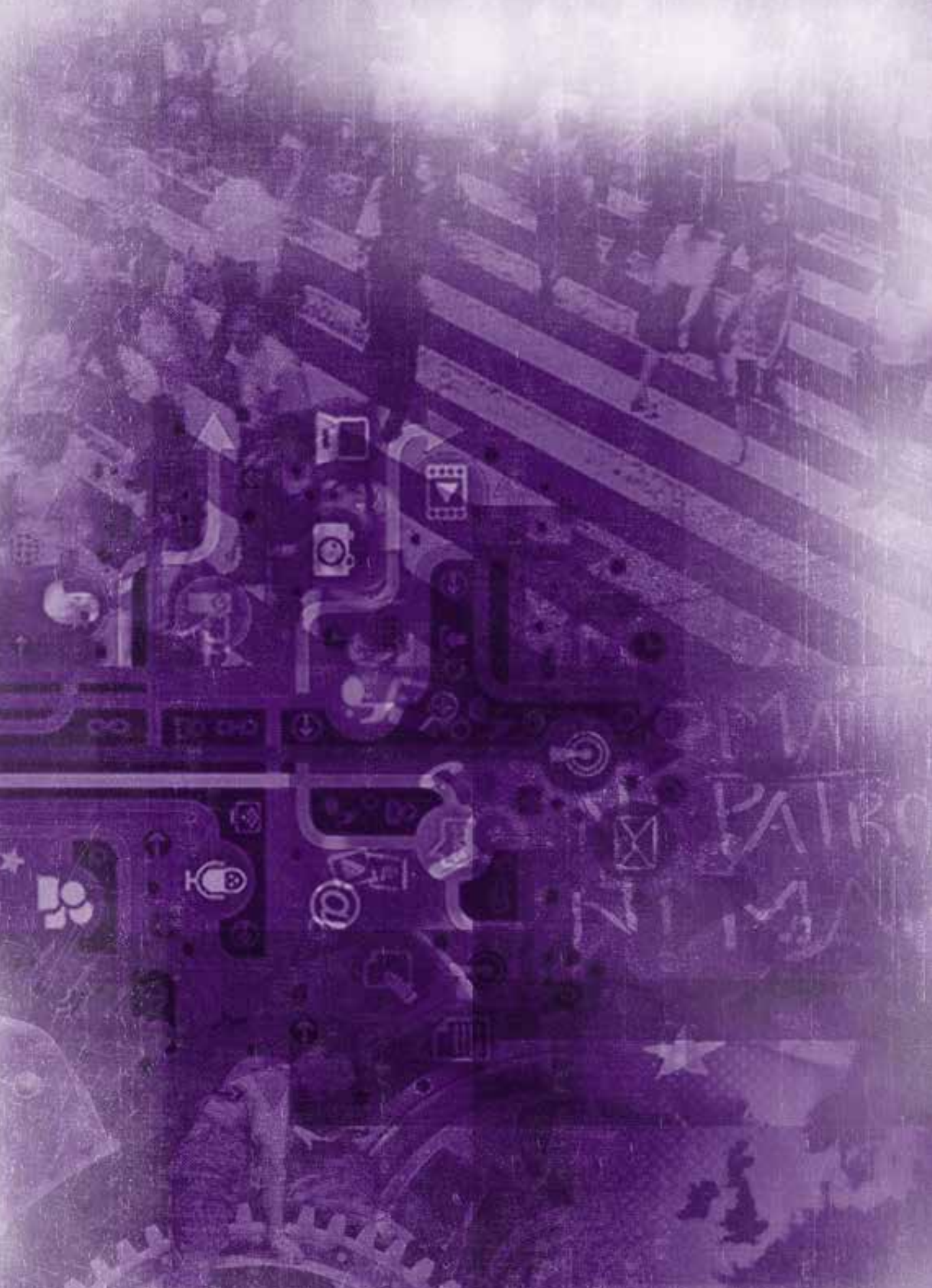

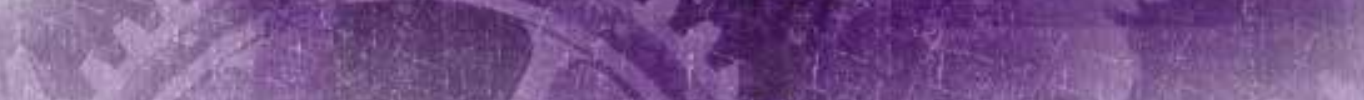




\title{
CAOS Y CATÁSTROFE. UN DEBATE SOBRE LAS TEORÍAS CRÍTICAS ENTRE AMÉRICA LATINA Y EUROPA
}

\author{
Víctor Silva Echeto (2014) \\ Ed.: Gedisa \\ Barcelona, 128 páginas \\ DoI: 10.15213/redes.n11.p320 \\ LUCÍA BENÍTEZ EYZAGUIRRE
}

Caos y catástrofe. Un debate sobre las teorías criticas entre América Latina y Europa muestra un itinerario para revisar las teorías de la comunicación a partir de las problemáticas que la posmodernidad y la colonialidad proyectan sobre el conocimiento de la comunicología, para rebatir y discutir postulados diseñados por el poder y sus discursos, para trazar modos de intervención con los que afrontar el presente y los imaginarios del futuro. El planteamiento caótico busca atomizar los postulados desde la acción crítica a partir de la problemática del análisis de la cultura cuando se inserta en los cruces de la economía y la política, en su impacto en lo social y lo humano. La referencia a la catástrofe recuerda que la estabilidad de los sistemas se enfrenta siempre a cambios repentinos e imprevisibles a partir de los cuales se reinicia el pensamiento y el equilibrio.

A través de la crítica a la producción intelectual sumisa y reproductiva que termina enunciando postulados de voluntad doctrinal, Víctor Silva plantea una profunda revisión que deslocaliza sus enunciados para ponerlos en discusión atacando estas estructuras desde lo social y contextual. La deconstrucción de Caos y catástrofe mapea las expresiones del capitalismo cultural en tres líneas de expresión consolidadas y de influencia: lo cultural enclavado en la comunicación-mundo como ámbito político, lo económico, además de la integración de la expresión líquida de lo visual, a través de "un análisis genealógico sobre los regímenes escópicos de la modernidad y la crisis del ocularcentrismo tras el ascenso de la multiplicidad de miradas" (p. 117).

En este último aspecto, en la capacidad de influencia y de cambio de los imaginarios analizados desde las estrategias visuales, se encuentra el mayor acierto de la revisión de Silva Echeto. Cuestionar, por fin, no las propuestas visuales sino las miradas como un debate atomizador sobre la lectura, 
entendida hasta hace pocos años como exclusiva y fruto de una propuesta intencional y de voluntad unidireccional. La "decolonialidad de las miradas" como problema trasciende ya el paso "de los medios a las mediaciones" para insertar en lo social las prácticas de consumo y la apropiación de los mensajes parte de la producción de ideología y de su capacidad para la acción política, de la autonomía personal de la crítica. Así, el campo de la estética se transforma en terreno ideológico, "en una estética como estesia y anestesia provocada por los medios de comunicación” (p.62).

Al margen de la comunicación mediática, trata de plantear alternativas a la "comunicación como dominación" que planteó Martín-Barbero, a través de la producción de nuevas formas de sociabilidad, de relación entre subjetividades. Los escritos de Deleuze y Foucault le sirven para exponer las complejidades de lo visible y de lo enunciable como crítica de la representación. Sin embargo, el recorrido deja todavía pendiente la referencia a lo 'no visible' como no pensable, a los imaginarios estériles por la ausencia de las proyecciones de futuro y de acción, que entran en una vía muerta e improductiva. Porque "si tradicionalmente el poder es lo que puede ser visto, en la disciplina son los sujetos de poder los que deben ser vistos" (p.114), no cabe duda de que lo invisible precisa una nueva mirada.

Sin embargo, tanto en la renovación de la mirada como en la crítica ideológica y en el recurso a la revisión del pasado, de nuevo se muestra ausente la cuestión de la perspectiva de género, olvidada como en otro tiempo la colonialidad, aun cuando tiene la misma fuerza de cuestionamiento si sus raíces en el patriarcado y el poder son comunes. Pero también porque es un campo de la autonomía, de la emancipación y del empoderamiento, de la igualdad y de la diversidad con la que deconstruir "la mirada única".

Pero además, introduce el 'afuera' en el campo de la crítica, en la integración de la diversidad como un reto, como una enmienda a la totalidad que pone en evidencia la necesidad de incluir las perspectivas, trayectorias despreciadas, porque precisamente son éstas las que desbordan con mucho los límites del sistema. Su propuesta de intervención desde estos límites, desde la acción y la pasión, busca la fuerza transformadora a partir de un presente situado no sólo en las geografías del capital y la cultura sino en el tiempo que se densifica en función de las explicaciones del pasado que todavía se proyectan sobre la ideología y la crítica, sobre el papel de la cultura y de la política.

El caos y la catástrofe de la colonización del pensamiento y de los imaginarios se cuestionan también sobre el más reciente papel de la conectividad, discutiendo la comunicología centrada en la mediología. Por ello, combate el mito del libre acceso y de la ilusión de una sociedad igualitaria en sus redes 
horizontales con Flusser y sus propuestas sobre las tecnologías y la recepción, pensadas desde la periferia, desde las fronteras y sobre todo desde el sur. Entre ellas, los juegos de pantallas mediatizadas, la comunicación como inacción de Rancière, como la contradicción de la 'acción comunicativa'.

$\mathrm{El}$ abordaje de la teoría como parte de la práctica le conduce a un innovador planteamiento de los desplazamientos culturales, de los intersticios entre los campos de la comunicación y de las disciplinas donde ganan terreno nuevas visiones y propuestas fruto del cruce cultural, de la aceptación popular y de lo masivo. Siguiendo el sendero trazado por los estudios culturales, Silva encuentra en lo liminar de la comunicación - en sus tensiones y contradicciones - el lugar necesario para la crítica entre el roce y el desgaste de los saberes instituidos, el impulso para asumir las rupturas que contradicen que alguna vez el mundo fuera orden. 